\title{
Protective effect of Centella asiatica extract and powder on oxidative stress in rats
}

\begin{abstract}
The effect of Centella asiatica extract and powder in reducing oxidative stress in SpraqueDawley rats was evaluated. Lipid peroxidation was monitored by measuring malonaldehyde (MDA) level in blood. Activities of free radical-scavenging enzymes (superoxide dismutase and catalase) were determined using $\mathrm{H} 2 \mathrm{O} 2$ decomposition and nitrobluetetrazolium reduction, respectively. Results showed that administration of $\mathrm{H} 2 \mathrm{O} 2$ $(0.1 \%)$ in drinking water of the rats, for 25 weeks, increased the malonaldehyde levels in erythrocytes of all the rats. However, rats receiving C. asiatica extract, powder and atocopherol had lower MDA levels than did the other rats, which indicates, decrease lipid peroxidation in these rats. Increase in catalase activity of the rats appears to be a response to $\mathrm{H} 2 \mathrm{O} 2$ accumulation. The decrease in the activity of superoxide dismutase in C. asiatica- and a-tocopherol supplemented rats suggested a lower requirement for the enzyme and this indicates the protective effect of the plant in combating oxidative stress undergone by the rats. Results revealed that $\mathrm{C}$. asiatica extract and powder may ameliorate $\mathrm{H} 2 \mathrm{O} 2$-induced oxidative stress by decreasing lipid peroxidation via alteration of the antioxidant defence system of the rats.
\end{abstract}

Keyword: Centella asiatica, Oxidative stress, Malonaldehyde, Antioxidant enzymes 